\title{
Automated Irrigation and Fertigation System Applying Sensing Technology
}

\author{
Mahyuzie Jenal $^{1^{*}}$, Hakimi Zikri Nasirin ${ }^{1}$, Nur Aida Nabilah Mohd Razali @ \\ Kamaruddin $^{1}$, Syed Amiruddin Hilmi Sayed Mohd Albakir ${ }^{1}$, Ummi Sorfina \\ Rosmadi $^{1}$, Zureen Az Athira Z. Ahmad Rosly ${ }^{1}$
}

${ }^{1}$ Faculty of Electrical and Electronic Engineering,

Universiti Tun Hussein Onn Malaysia, Parit Raja, Batu Pahat, 86400, MALAYSIA

*Corresponding Author

DOI: https://doi.org/10.30880/jeva.2021.02.02.009

Received 12 July 2021; Accepted 21 December 2021; Available online 30 December 2021

\begin{abstract}
Internet of Things (IoT) is the most discussed topic nowadays and it finds many applications in various industries. The development of efficient agricultural systems has become essential to address the challenges of feeding the enormous and ever-increasing population around the globe. One way of dealing with this is to expand agricultural production standard and quantity. An integrated IoT system with irrigation and finishing on the market was missing. To increase production efficiency, farmers shall collect massive data from various devices. The system's effectiveness depends on the performance of the sensor under various climate changes. The network and a closedloop feedback system need to be connected to the system for maximum operational capacity. The module of the Soil Moisture Sensor and the MCU ESP8266 V2 MCU Node, the float switch and the 5V Optocoupler relay module are used in this project. The remote control of the system is a mobile application. If the moisture level in the soil reaches the desired value, it will stop water supply. The project could be expended on a larger scale in the future and the system may also be developed with solar energy rather than batteries.
\end{abstract}

Keywords: Internet of Things (IoT), agricultural, sensor, closed-loop feedback system, mobile application

\section{Introduction}

Internet of Things (IoT) is a well-known trend nowadays and these systems have found their applications in the field where it eases human labor shortage, or for the initiative to adopt more advanced technology or both [1]. Devising proper farming practices has become essential to face the big challenges within the agricultural industry to feed the tremendously rising population. One of the methods to handle this issue is to extend the standard and quantity of the agricultural production by using IoT technology to make farms more "intelligent" and more "connectivity" through the so-called "precision agriculture" and "smart farming" [2]. Over the past 15 years, farmers started using computers and software systems to arrange their financial data and keep track of their transactions with third parties [3]. Furthermore, there was a lacked integrated IoT system with irrigation and fertigation within the market. The result of automated irrigation and fertigation depends on the algorithm of the system in solving the prevailing problem. For the system to work in optimum capacity, it is connected to the network and a closed-loop feedback system to maximize the power of interaction. Within the Internet era, farmers must collect and evaluate an enormous amount of data from various devices (e.g., sensors, etc.) to become more efficient in production. The effectiveness of the system depends on the sensor performance in different climate changes [4]. 
Smart farming is a high-tech, capital-intensive method for producing safe, nutritious food for the masses. It is the incorporation of new information and communication technologies (ICT) into agriculture. In IoT-based smart farming, a created framework is for inspecting the yield field with the help of sensors and robotizing the water system framework [5]. Farmers can monitor field conditions from any location and use sensors to monitor yield and water levels. The proposed system includes several sensors as well as a controlling device. The combination is in such a way that output were not harmed for any reason. Any incorrect circuit link will cause the entire device to malfunction. To begin with, Blynk is an IoT (Internet of Things) stage from which you can easily and monitor remotely. It is conveniently accessible for operating systems such as MAC, Windows, and Linux, and it runs on the platform that comes with it. Each of them has a changed microcontroller on the board that recognizes the data as code [6]. Besides, when the system running usually the moist sensor will detect the soil moisture in percentage. While the value of soil moisture above $50 \%$ the pump is turn OFF. If the value of soil moisture below 50\% the pump is, turn ON and return OFF automatically synchronous with the system.

Next, the Node MCU ESP-12E is a coordinated version of the well- known ESP8266, a Serial to Wi-Fi System on a Chip (SoC) that debuted in 2013. An IC manufacturer specializing in the creation of RF chips, especially Wi-Fi, designed the ESP8266. Several modules on the market use the ESP- 8266 chip, which referred to as the ESP-NN. [7]. The soil sensor includes two measurements that used as to calculate the volumetric substance of water. When there is more water, the dirt produces more fuel, implying that there would be less obstruction. This sensor is compatible with two modes: analog and advanced. Initially, we will link it in analog mode, and then we will use it in digital mode. Fifth, there is a one Channel 5V Relay Board Module for Arduino PIC AVR DSP ARM. A wide range of microcontrollers, including Arduino, AVR, PIC, ARM, and others, can regulate it. The high ebb and flow hand-off is included. Finally, yet importantly, a basic water pump to show how the flow of waterworks and how it responds to the relay board. This would also increase the amount of water discharged per minute. The water pumps were energized by an alternating current (AC) source.

The benefits of this works are this product can give benefits to farmer where they do not need to go to the farm daily to water their plant. They can monitor the irrigation process through their phone. This design also can reduce a human labor where the farmer does not need to go to the farm every day and water their plant manually. The competitors are the existing system nowadays. However, most of the project are targeting a big scale farmer where this project is targeting a B40 person who does not have a huge capital. Industries use automation to control machine, but the same technique is not suitable for use in agriculture area due to its high in cost [8]. Human intervention can be reduced by proper method of irrigation [9]. Applying the internet of things to the highly effective and safe agricultural production has a significant impact on ensuring the efficient use of water resources as well as ensuring the efficiency and stability of the agricultural production [10]

\section{Methodology}

This project implements on automated irrigation and fertigation system. Extensive literature review has been conducted on the sensors, water pump, and system as to identify and survey on methods of developing and applying the system. This section provides three different flowcharts that will be explain accordingly to their sub-sections. The first flowchart is how the mechanism irrigation and fertigation system operated. Then, the second flowchart is the development in building the mechanism. Lastly, flowchart of how data collection conducted.

\subsection{Flowchart of Automated Irrigation and Fertigation System}

As per the Figure 2.1, the system begins with the system connects with Wi-Fi, if not the system will try again to connect with Wi-Fi. Then, proceed to soil moisture sensor reading and accumulate data of the moisture reading in a temporary cloud. Moisture sensor process afterwards depends on float sensor if there is water in the tank to proceed to the next process. Next, the observation of the data are on two stages, which will affect the decision on motor pump. The stages are moisture level greater than $50 \%$ and less than $50 \%$. If the moisture reading is above $50 \%$, the data will be stored. If not, a signal sent to float sensor to identify whether there is water in the tank. If there is water, the motor pump will turn on, to supply water until the moisture level increase. The flowchart of the system as referred below. 


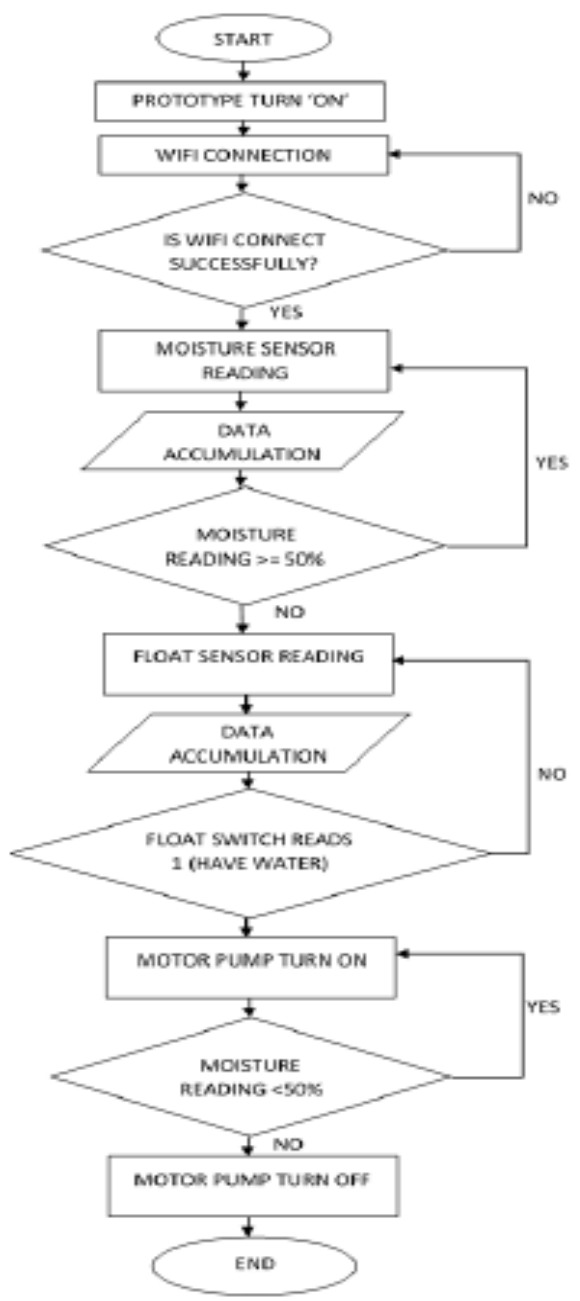

Figure 2.1 - Flowchart of the automated irrigation and fertigation system 


\subsection{Flowchart of Development of the Automated Irrigation and Fertigation System}

According to the Figure 2.2, the development of the system is first beginning with conducting literature review and survey. Then, design and selection of sensor and Wi-Fi module according to cost and circuit diagram proposed. Next, identify the load and check whether the design meet objective 1 or not. If not, the load identification and system design need to proceed. If yes, the researcher proceeds to developing the algorithm for the system and assemble for linking the coding to the hardware. Along the way, the system undergo system troubleshoot and rectification until it achieves objective 2. Then, proceed to collecting data by categorize day of testing until objective 3 is achieved. Lastly, proceed to report writing. The flowchart of the development of the system can be refer below.
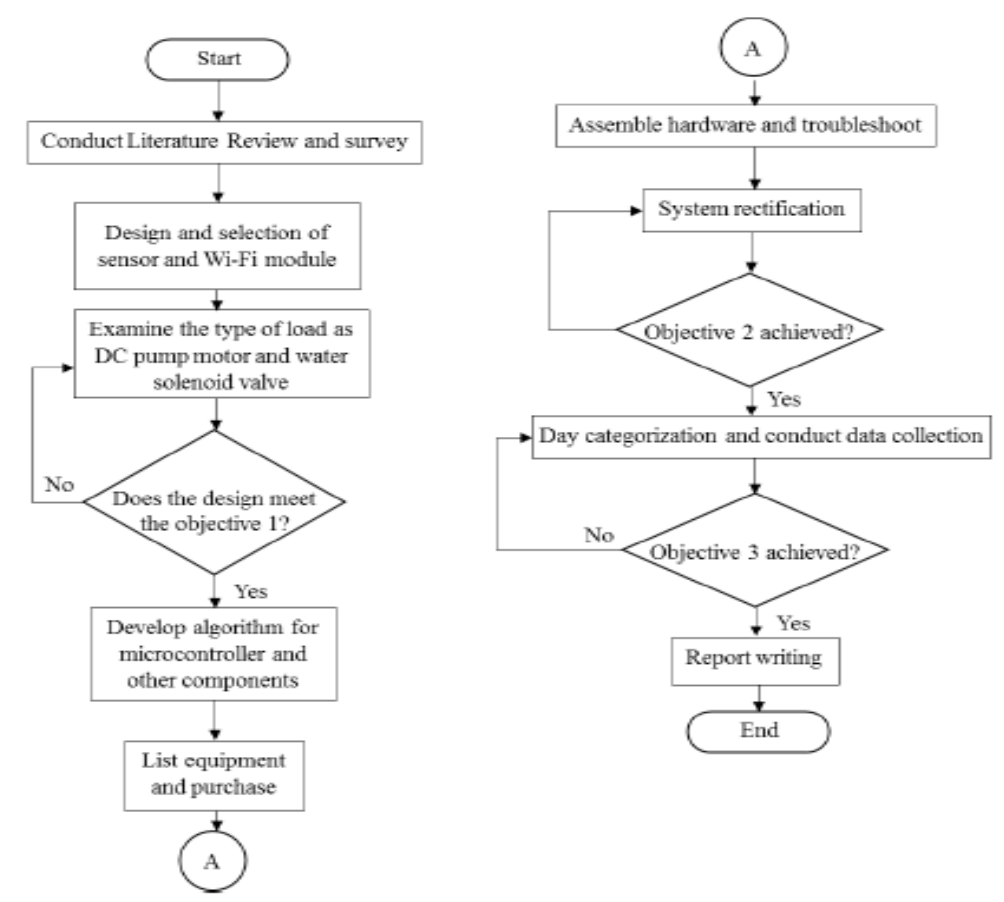

Figure 2.2 - Flowchart of development of the automated irrigation and fertigation system

\subsection{Flowchart of Data Collection}

According to the Figure 2.3, the data collection flowchart starts with day categorization where the test according to the weather condition. Then, observe the reading of the soil moisture through the sensor. Next, proceed to observing the functionality of the motor pump where it should supply water when moisture reading exceeds certain threshold. Lastly, compare the result between with and without the motor pump

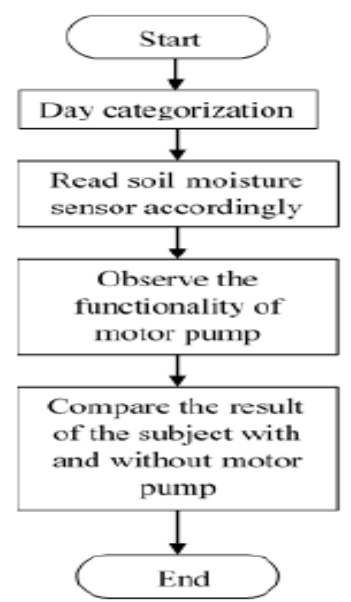

Figure 2.3 - Flowchart of data collection 


\subsection{Hardware Circuit Design}

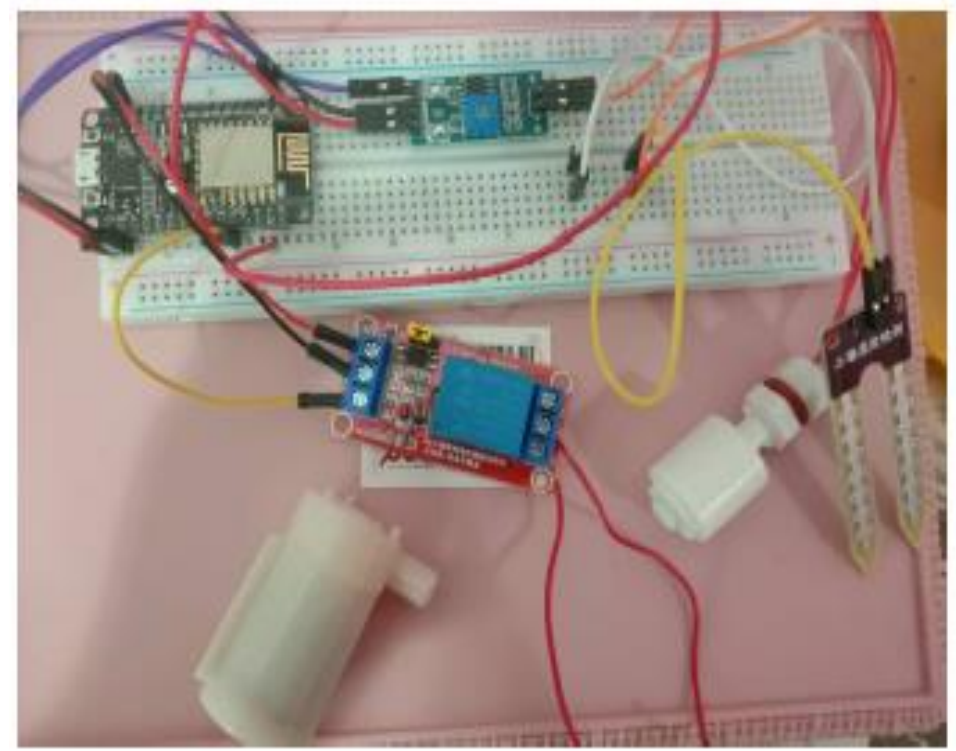

Figure 2.4 - The hardware design of the system

The embedded sensors used in the IoT-based system are the source of sensing and cost effectively and it can record and analyses data. The proposed smart IoT system as shown in Figure 2.4 employs some component together to gather data and the Node MCU is to transfer the value to the server. As we can see in Figure 2.4, a soil moisture sensor is to detect the soil moisture. Then, the single channel relay used, in order to control high voltage and the high current load. Next, the PP float switch used as water level sensor to know whether there is water in the tank or not. Lastly, the water pump use to draws in the liquid at its centre and it will throw out the liquid through an opening at the side of the casing due to the centrifugal force.

In this project, the complexity depends on the irrigation management, it is a complex decision-making process in order to determine when and how much water to apply to a growing crop. Next, the project identifications are complex and difficult to prepare, implement and to evaluate. Other than that, the project covered large infrequently areas of knowledge and had many components that involved. Next, it is not easy to write the software for the Automated Irrigation and Fertigation System and upload it in the Node MCU to run the water pump and connect to the Blynk Apps. Then, with the wide range of sensors that are available now, it can be complex to choose because the correct use of information for decision-making purposes need for specialist expertise and dedication of time and effort. Lastly, to do the coding, need to understand the functions, variables, objects, data types, and a lot more terms to be type out and transformed into code sometimes is complex to understand especially when there is a lot of variables and objects involved.

\section{Result and Discussion}

\subsection{Circuit Schematics}

The circuit configuration for this system shown in Figure 3.1. There are five important hardware was used which consist of main board for controlling is Node MCU ESP8266. Soil moisture sensor had three ports; Voltage, Ground, Signal. The signal port connected to analog pin in Node MCU. For the water pump, it needed external supply to supply the $5 \mathrm{~V}$ relay. From normally open (NO) port was connected to positive port in water pump and negative port water pump connected with negative wire $5 \mathrm{~V}$ supply the positive wire supply was connected with COM port in relay. To control the relay, supply and voltage power was connected to the microcontroller board while the IN port was connected to D4 port on Node MCU. Lastly, the PP Float Switch connected to port D2 on Node MCU and the other one port grounded. The coding uploaded into the Node MCU and monitoring process throughout the testing observed through Blynk Apps. 


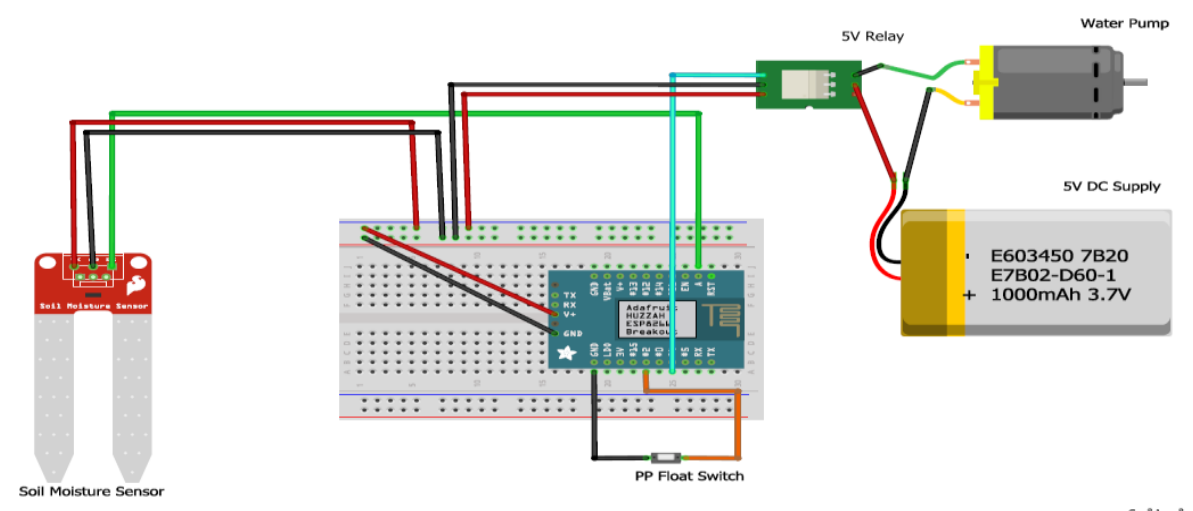

Figure 3.1 - Connection of circuit using Blynk/ Fritzing? Apps

\subsection{Test Setup}

The test were conducted for two days due to hardware limitation. On the first day, the system was placed without water pump and on the second day, the water pump was turned on to demonstrate the requirements of this system to crops. The irrigation system was placed under a real weather condition for 9 hours from 9 AM to 6 PM. The parameter that being observed is the soil moisture reading since the priority for this project is the soil moisture.

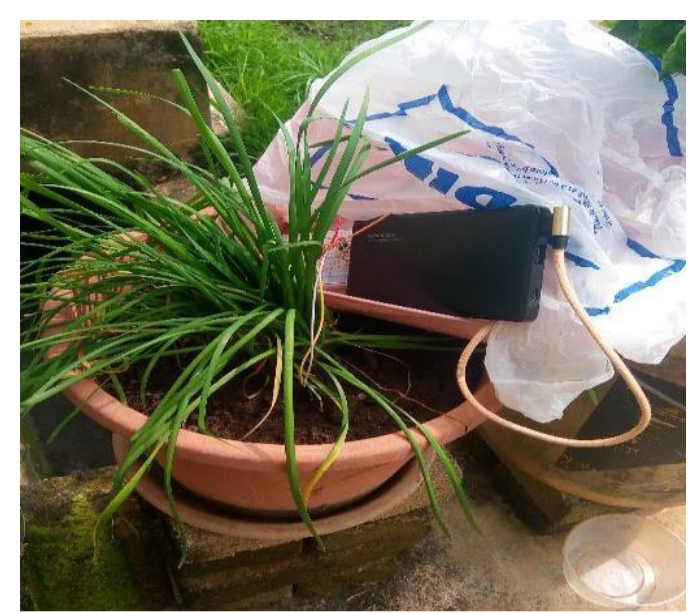

Figure 3.2 - The setup for testing at day 1

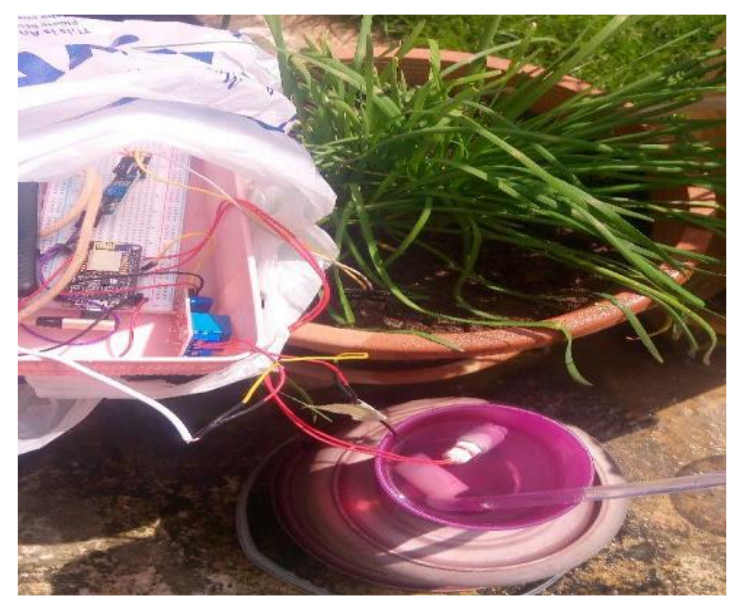

Figure 3.3 - The setup for testing at day 2 
Based on Figure 3.2, the system was powered by power bank since the supply for Node MCU is 5V and supply for the relay also $5 \mathrm{~V}$. On day two, the setup was included water pump to irrigate the plant as in Figure 3.3.

\subsection{Soil Moisture Reading}

Data is collected for 9 hours with three hours' interval. The results of testing can be refer in Table 3.3 below.

Table 3.3 - Testing results

\begin{tabular}{|l|c|c|c|c|c|}
\hline \multicolumn{3}{|c|}{ Day 1: Without Water } & \multicolumn{3}{c|}{ Day 2: With Water } \\
\hline Time & $\begin{array}{c}\text { Soil } \\
\text { Moisture } \\
(\%)\end{array}$ & Weather & Time & $\begin{array}{c}\text { Soil } \\
\text { Moisture } \\
(\%)\end{array}$ & Weather \\
\hline $\begin{array}{l}9.00 \\
\text { AM }\end{array}$ & 60.62 & Sunny & $\begin{array}{l}9.00 \\
\text { AM }\end{array}$ & 60.15 & Sunny \\
\hline $\begin{array}{l}12.00 \\
\text { PM }\end{array}$ & 59.24 & Sunny & $\begin{array}{l}12.00 \\
\text { PM }\end{array}$ & 58.63 & Sunny \\
\hline $\begin{array}{l}3.00 \\
\text { PM }\end{array}$ & 48.02 & Sunny & $\begin{array}{l}3.00 \\
\text { PM }\end{array}$ & 62.46 & Sunny \\
\hline $\begin{array}{l}6.00 \\
\text { PM }\end{array}$ & 53.37 & Raining & $\begin{array}{l}6.00 \\
\text { PM }\end{array}$ & 54.06 & Sunny \\
\hline
\end{tabular}

According to Table 3.3, the soil moisture in day 1 is decreasing and because of rain at around 5.30 pm, the reading increase again to $53.37 \%$. The reading for the soil before raining was $47.41 \%$. Therefore, without the irrigation system, the soil moisture will keep decreasing because of hot weather and farmer need to irrigate their crops regularly. When the irrigation system is applied, the soil moisture will always be at the proper level; in this case $50 \%$ and above. The reading of soil moisture increased from $58.63 \%$ to $62.46 \%$ because the system just irrigated the plant between those periods. Therefore, this result shows that the system is reliable and functioning successfully.

\subsection{Voltage and Current Reading}

The voltage and current reading is important as it, to monitor the voltage and current requirements during the system working. The value is measured by using voltage and current USB meter as in Figure 3.4

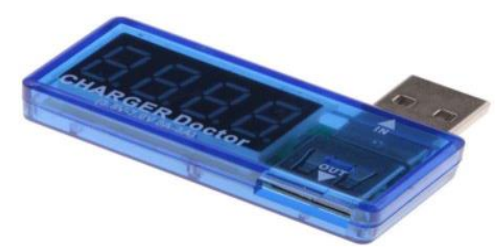

Figure 3.4 - Voltage and current USB meter

The parameter that involved is voltage and current reading for Node MCU and relay when the system turns on and off. The data was presented in Table 3.4.

Table 3.4 - Results for voltage and current according to condition

\begin{tabular}{|c|c|c|c|c|}
\cline { 2 - 5 } \multicolumn{1}{c|}{} & \multicolumn{2}{c|}{ Condition 1: On } & \multicolumn{2}{c|}{ Condition 2: Off } \\
\cline { 2 - 5 } \multicolumn{1}{c|}{} & NodeMCU & Relay & NodeMCU & Relay \\
\hline $\begin{array}{c}\text { Voltage } \\
\text { (V) }\end{array}$ & 5.07 & 5.06 & 5.07 & 5.06 \\
\hline $\begin{array}{c}\text { Current } \\
\text { (A) }\end{array}$ & 0.12 & 0.19 & 0.04 & 0 \\
\hline
\end{tabular}

The voltage is constant for both condition because the supply is remains in either condition 1 or condition 2 . The difference was in current consumption where when the system is functioning, the Node MCU draws $0.12 \mathrm{~A}$ and the relay draws $0.19 \mathrm{~A}$ of current. This shows that this system will consume about $4.6 \mathrm{~W}$ during operation time and $0.2 \mathrm{~W}$ during 
off time. The improvement, the researcher would suggest by applying a sleep-mode for the Node MCU and set a periodic time for the Node MCU to operate, read the moisture sensor reading and execute any watering process if needed and turn off again to save energy.

\section{Conclusion}

The purpose of this project is to design a system that fit for large and small-scale consumers to make it more effective. The different sensors, which are soil moisture and water level with different devices such as water pump, battery, LCD, and solenoid valve, is use in this project. Several design criteria can be use in the system. The sensor used is perfect for detecting and sending signals to Arduino. It will also control the water pump and open the solenoid valve used in this system. Mobile application such Blynk apps will allow the user to monitor the soil moisture and water level. It also will allow the user to monitor the soil moisture and water level. The LCD will display whether the soil is dry or moist. The basic idea for sensors that used is to monitor the level of moisture and using the pump to supply water. The results will indicate that if the level of moisture in the soil is reaching the desired value, it will stop supply the water. The water level sensor is to detect whether the water is in the tank or not. For the future project, it can transfer the project to a large scale. Then, also can develop the system by using renewable energy, which is solar power instead of batteries. It will also help to reduce future costs. Lastly, the temperature sensor also can be included to measure the temperature of its environment.

\section{Acknowledgement}

The Author would like to thank the Faculty of Electrical and Electronic Engineering, Universiti Tun Hussein Onn Malaysia for the facilities that has been provided and for its support.

\section{References}

[1] O. Vermesan and P. Friess, Eds., Internet of things applications: From research and innovation to market deployment. Gistrup, Denmark: River, 2014

[2] N. Putjaika, S. Phusae, A. Chen-Im, P. Phunchongharn and K. Akkarajitsakul, "A control system in an intelligent farming by using arduino technology," 2016 Fifth ICT International Student Project Conference (ICT-ISPC), Nakhon Pathom, 2016, pp. 53-56

[3] M. T. Batte, "Changing computer use in agriculture: evidence from Ohio," Comput. Electron. Agric., vol. 47, no. 1, pp. 1-13, 2005

[4] J. J. Amalraj, S. Banumathi, and J. Jereena, "IOT Sensors and Applications: A Survey", International Journal of Scientific \& Technology Research, Volume 8, Issue 08, Pages: 998-1003, 2019

[5] Y. Na, Y. Guo, Q. Fu, and Y. Yan, “An acoustic traffic monitoring system: Design and implementation," in 2015 IEEE 12th Intl Conf on Ubiquitous Intelligence and Computing and 2015 IEEE 12th Intl Conf on Autonomic and Trusted Computing and 2015 IEEE 15th Intl Conf on Scalable Computing and Communications and Its Associated Workshops (UIC-ATC-ScalCom), 2015

[6] Chetan Dwarkani M, Ganesh Ram R, Jagannathan S, and R. Priyatharshini, "Smart farming system using sensors for agricultural task automation," in 2015 IEEE Technological Innovation in ICT for Agriculture and Rural Development (TIAR), 2015

[7] Nikesh Gondchwar, R. S. Kawitkar, "IOT based smart agriculture," International journal of Advanced research in computer and Communication Engineering (IJARCCE), vol. 5, no. 6, Jun. 2016

[8] S. Parthasarathy, T. Arun, S. Hariharan, and D. Lakshmanan, "Smart irrigation system," Int. J. Innov. Technol. Explor. Eng., vol. 8, no. 8, 2019, doi: 10.2139/ssrn.3462943

[9] S. Rawal, "IOT based Smart Irrigation System," Int. J. Comput. Appl., vol. 159, no. 8, 2017, doi: 10.5120/ijca2017913001

[10] P. Naik and K. Katti, “Automation Of Irrigation System Using IoT,” 2018 Fourth Int. Conf. Adv. Electr.Electron. Information, Commun. Bio-Informatics, vol. 8, no. 1, pp. 77-88, 2018 